\section{Duopoly innovation with monopoly debater}

\author{
You-hua CHEN
}

College of Economics \& Management, South China Agricultural University

\section{Pu-yan NIE}

Jin-bo Huang

School of Finance, Institute of Guangdong Economy \& Social Development, Guangdong University of Finance \& Economics (GDUFE)

\section{Abstract}

Purpose - This paper highlights the interaction between innovation and financial structure under duopoly with a monopoly debater.

Design/methodology/approach - By game-theory approaches, we characterize effects of debt levels on innovative investment with limited liability effect.

Findings - This paper argues that higher debt levels increase both innovative investment and output. Both higher debt rate and higher debt levels act as commitment to reduce opponent firms' net profits. Net profit for unit debt is reduced with higher debt level and higher debt rate.

Originality/value - This study extends Brander and Lewis's (1986) to innovative situation and no interior point solution is restricted.

Keywords - Financial structure; innovation; monopoly debater; corporate finance; commitment
Received on

$04 / 23 / 2015$

Approved on

$10 / 13 / 2016$

\section{Responsible editor:}

Prof. Dr. André Taue Saito and Prof. Dr. João Maurício Gama Boaventura

\section{Evaluation process:}

Double Blind Review

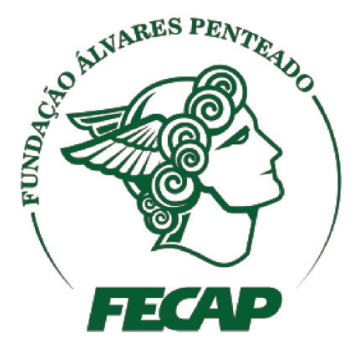

Review of Business Management 


\section{Introduction}

Modigliani and Miller's (1958) study has a profound influence on corporate finance theory and industrial organization theory, because the M-M theory isolates the interaction between capital market and product market by stating that capital structure has no impact on the value of the firm. But Brander and Lewis (1986) make a great challenge to the $\mathrm{M}-\mathrm{M}$ theory because they captured the relationship between financial structure and output of firms based on Jansen and Meckling's model (1976) initially. Their studies found that higher debt levels improved quantity of output and the value of the firm. In other words, Brander and Lewis (1986) argued that firms' values have something to do with their capital structure, and their study established an inherent connection between capital market and product market. Limited liability effect is the connecting bridge between those two markets.

In a limited liability firm, debt is the senior claimant to firm's returns and equity is the residual claimant. The limited liability company arose from business owners' desire to adopt a business structure that allows them to operate like a traditional partnership. A limited liability has deep effects on firms' behaviors in practice. Because of limited liability effects, firms' and investors' strategies all differ from those without debt. For instance, while traditional corporations can provide only one class of the company stock, limited liability companies can offer several different classes with different rights. In addition, based on the low of American, traditional corporations are limited to a maximum of 75 individual shareholders (who must be U.S. residents), whereas an unlimited number of individuals, corporations, and partnerships may participate in a limited liability company. Furthermore, a limited liability company also carries significant tax advantages over the limited partnership. Unless a partner in a limited partnership plays an active role, his or her losses are considered passive losses and cannot be used as tax deductions to offset active income. A limited liability combining with debt financing will have significant influence on firms' competition decisions.

There is no doubt that there are inherent relationships between capital market and product market, so it is quite important to notice the interaction between finance structure and output market behavior of firms. Many studies focused on the relationships between firm's capital structure and its competition behaviors in the product market and different or even opposite conclusions are obtained. That means more research about this issue is needed to reveal the interactions between firm's capital structure and its competition behaviors.

This study closely relates to Brander and Lewis (1986). Unlike them, we characterize two producers with monopoly debater in order to identify the effect of price discrimination of debt on output market and innovation decisions. Monopoly debater (or monopoly capital market) means that there is only one debater and both producers must borrow debts from the same debater. In developing countries, it is very difficult for small businesses to borrow money from banks and the bank plays a monopolization position. Therefore, it is very interesting to address monopoly debater in developing countries.

Innovative investment is introduced under special cases of Brander and Lewis (1986). Compared with Brander and Lewis (1986), this study has no restriction of interior point solution. Different from other studies, such as Myers's (1977), this paper assumes that debt levels in the first stage are given, which allows us to focus on the effects of debt on the output and innovation decisions. Contributions of this study are outlined below.

First, Blander and Lewis (1986) restricted their attention to firms' output quantity. But this paper expands their framework to analyze innovative investment behaviors. Second, imperfect competition structures are more ordinary in industrial organization studies. We expand capital market from perfect competition 
to monopoly, which makes it easy to analyze the effect of the cost of debt financing on output market competition. Finally, optional solutions are more common, because this study has no restriction of interior point solution. Two factors lead Blander and Lewis (1986) to ignore corner solution: abstract function analyses and to simplify the model analyses. But corner solution is quite common in reality because capital and other resource constraints make it impossible to carry out first-order condition decision for firms.

The rest of this paper is organized as follows: Literature review is outlined in the next section. Duopoly model with monopoly debater is established in section 3 . The model is analyzed in Section 4. The effects of capital structure on shareholder value and debt value are all characterized. The debt levels are also discussed. Some remarks of conclusions are presented in the final section.

\section{Literature review}

Most of the studies that focus on effects of limited liability on innovation are based on corporate financial perspective. Jacob and Spaeter (2016) capture effects of limited liability on risks and technological change. Their study found that technological change improves welfare but leads to full risk internalization under limited liability. Wang, Wang, Liang, Tsai and Mai (2016) investigated patent licensing investment with limited liability under financial structure. The results showed that, under Cournot competition, a firm would choose royalty licensing if the mean-preserving variance of demand is large. Schmitz (2012) stated that limited liability leads to overinvestment under limited liability but investor's investment incentives will decrease with the increase of bargaining power. Interestingly, Norman (2004) declared that effects of limited liability can even lead to the wrong choice of technology.

Much research connecting corporate finance and industrial organization emerges prominently (Baum, Chakraborty, \& Liu,
2010; Nie, Yang, Chen \&Wang, 2016; Nie \& Chen, 2012; Showalter, 2010; Ramalho \& Da Silva, 2009; Riordan, 2003). Brander and Lewis (1996) captured effects of debt on firm and its rivals product market behavior and their conclusions showed that debt increases firm's outputs but decreases its rivals' because of effects of limited liability. Taking bankruptcy cost into account, Brander and Lewis (1998) further studied this topic at other aspects. Maksimovic (1988) discussed dynamic situations and derived some interesting conclusions. Chevalier (1995) verified this relationship between financial structure and output. But his study shows that debt decreases firm's outputs. Showalter's (1995) price competition model illustrated that the relationships between capital structure and outputs market behaviors depended on the uncertainty of demand market. Tarzijan (2007) recently explored entry deterrence with limited liability effects. Chowdhuri and Haller (2009) further studied this topic and derived some interesting conclusions. Cull, Demirgüç-Kunt and Lin (2013) recently remarked the relationship between financial structure and economic development. Bhattacharyya (2013) examined the effects of political origins on the financial structures. Uras (2014) addressed the effects of financial structure on the total factor productivity. Most of those studies are focused on quantity and price competition.

Some recent studies expand the topic to innovation behavior. Based on Brander and Lewis's (1986) study, Clayton (2009) investigated the relationships between investment and production market competition. And he stated that debt leverage leads to weaker outputs market competition. Chen, Nie and Wen (2015) examined the interaction between innovation and financial structure. Their study highlighted the joint effects of function of the random market environment variable and firm's outputs. Nie et al. (2016) even employed Brander and Lewis's (1986) framework to analyze carbon finance subsidies in renewable energy industry and their study showed 
that limited liability effects of debt have significant impacts on renewable energy investment.

\section{Model}

Model of duopoly in debt with limited liability effect is established in this section. Two firms produce $q=\left(q_{1}, q_{2}\right)$. Products of two firms are functionally identical and the cost incurred by production is different. This means that there are horizontal differentiations. The price of this product is $p$. This paper introduces a two-stage game: at the first stage, two producers decided their debt levels with prices $r_{i}$; at the second stage, given the debt levels, two producers compete both in the output market and in the innovative investment. Debt levels are given before output and innovative investment decisions (first stage), and the study only highlights the effect of debts on output and innovative decisions in the second stage.

\section{Consumers}

Given a constant $A>0$, the utility of consumers with quantity $q$ is

$u(p, q)=A q-\frac{1}{2} q^{2}-p q$.

The demand is induced by (1), which is stated as follows

$q=A-p$.

In general, $A>0$ is large enough such that demand is enough.

\section{Two firms}

Innovative investment of two firms is $I=\left(I_{1}, I_{2}\right)$ and for $i=1,2$, the operating profit of firm $i$ without considering debt is

$$
\pi_{i}\left(q_{i}, z_{i}, I_{i}\right)=p q_{i}-c_{i}\left(I_{i}\right) q_{i}+q_{i} z_{i}-\frac{1}{2} I_{i}^{2}
$$

where $z_{i}$ is a random variable which represents the effects of an uncertain environment on the fortunes of the firms. Random variable $z_{i}$ is uniformly distributed over interval $[\underline{z}, \bar{z}]$ associated with density function $f\left(z_{i}\right)=\frac{1}{\bar{z}-\underline{z}}$. The $z_{i}$ 's are independent and identically distributed, for $i=1,2 . c_{i}\left(I_{i}\right)$ represents the marginal cost incurred by production. $\frac{1}{2} I_{i}^{2}$ stands for the investment $\cos \mathrm{t}^{1}$. The above operating profit meets relations $\frac{\partial \pi_{i}}{\partial z_{i}}>0, \frac{\partial^{2} \pi_{i}}{\partial q_{i} \partial z_{i}}>0$ and $\frac{\partial^{2} \pi_{i}}{\partial q_{i}{ }^{2}}<0 . \frac{\partial \pi_{i}}{\partial z_{i}}>0$ indicates that higher value of $z_{i}$ yields higher operating profit. $\frac{\partial^{2} \pi_{i}}{\partial q_{i}{ }^{2}}<0$ represents the concavity of operating profit function, which guarantees that there is a unique solution for (3). Furthermore, market clearing conditions $q_{1}+q_{2}=q$ are always held.

\section{Shareholders}

Given debt level $D_{i}$ for $i=1,2$, the equity value of firm $i$, which goes to the shareholders after financing and production decision, is represented by $V_{i}$. After production occurs, by virtue of financial policies, this firm is obliged to pay creditors $D_{i}$ out of current profits. Debts of two firms come from a monopoly debater with different costs. Each firm sets its quantity and innovative investment to maximize the expected value to the shareholders. In a limited liability firm, debt is the senior claimant to the firm's returns and equity is the residual claimant. The value of shareholders and the corresponding notations are all similar to that of Brander and Lewis (1986).

$$
V_{i}\left(q_{i}, I_{i}\right)=\int_{\varepsilon_{i}}^{\bar{E}}\left[\pi_{i}\left(q_{i}, z_{i}, I_{i}\right)-\left(1+r_{i}\right) D_{i}\right] f\left(z_{i}\right) d z_{i}
$$


where $r_{i}$ is the rate of debate and $\hat{z}$ is completely determined by the relation ${ }^{2}$

$$
\pi_{i}\left(q_{i}, \hat{z}_{i}, I_{i}\right)-\left(1+r_{i}\right) D_{i}=0
$$

When $z_{i}=\hat{z}_{i}$, the operating profit of firm $i$ can just cover its debt obligations without anything left over. If $z_{i}<\hat{z}_{i}$, firm $i$ pays all its earnings to debt holders and earns zero. This state seems very bad. $z_{i} \geq \hat{z}_{i}$ indicates positive profits for firm $i . V_{i} / D_{i}$ stands for net profits of unit debt for firm $i$.

We further define debt value, which is also similar to that of Brander and Lewis (1986).

$$
W_{i}\left(q_{i}, I_{i}\right)=\int_{\underline{z}}^{\hat{z}_{i}} \pi_{i}\left(q_{i}, z_{i}, I_{i}\right) f\left(z_{i}\right) d z_{i}+\left(1+r_{i}\right) D_{i}\left[1-F\left(\hat{z}_{i}\right)\right]
$$

where $F\left(\hat{z}_{i}\right)=\int_{z_{i}}^{\bar{z}} f\left(z_{i}\right) d z_{i}$. (6) is the debt holders' expected values. $1-F\left(\hat{z}_{i}\right)$ is the probability of good state. The first term is the expected value for debt holders at the bad state, when the operating profit of firm $i$ is insufficient to meet debt obligation. The second term stands for states in which the creditors of firm $i$ are paid in full.

For the model given by (1)-(6), the following assumption is launched, which is similar to that in Vives (2008) or Sacco and Schmutzler (2011).

\section{Assumption}

$c_{i}\left(I_{i}\right)$ is convex and $c_{i}^{\prime}\left(I_{i}\right)<0$ for $i=1,2$.

$c_{i}^{\prime}\left(I_{i}\right)<0$ indicates that innovative investment efficiently reduces the incurred production cost. This hypothesis is extremely rational and very moderate, which appears in other papers of innovation theory, such as Sacco and Schmutzler (2011).

To simplify this problem, other factors, such as bankruptcy costs and tax advantages of debt, are not discussed, although these factors are all considerably important. From (3)-(6), (2) implies that price $(p)$ of the products is jointly determined by the outputs of two firms. Therefore, there is always strategic interaction in production levels.

\section{Main results}

Firstly, we show the existence and uniqueness of solution to the problem of maximizing the value of shareholders. For $i=1,2$,

(4) is restated as follows.

$V_{i}\left(q_{i}, I_{i}\right)=\int_{\hat{s}_{i}}^{\bar{z}}\left[\left(A-q_{1}-q_{2}\right) q_{i}-c_{i}\left(I_{i}\right) q_{i}+q_{i} z_{i}-\frac{1}{2} I_{i}^{2}-\left(1+r_{i}\right) D_{i}\right] f\left(z_{i}\right) d z_{i}$

with $q_{i} \hat{z}_{i}=\left(1+r_{i}\right) D_{i}-\left[\left(A-q_{1}-q_{2}\right) q_{i}-c_{i}\left(I_{i}\right) q_{i}-\frac{1}{2} I_{i}^{2}\right]$.

\subsection{Discussions of the uncertain environment}

(1) If $\hat{z}_{i}<\underline{z}$ for $i=1,2$, (7) is rewritten as follows.

$V_{i}\left(q_{i}, I_{i}\right)=\left(A-q_{1}-q_{2}\right) q_{i}-c_{i}\left(I_{i}\right) q_{i}-\frac{1}{2} I_{i}^{2}-\left(1+r_{i}\right) D_{i}+\frac{1}{2}(\bar{z}+\underline{z}) q_{i}$.

If $\hat{z}_{i}<\underline{z}$ for $i=1,2$, by virtue of (8), we have the following first-order optimal conditions

$\frac{\partial V_{i}\left(q_{i}, I_{i}\right)}{\partial q_{i}}=\left(A-q_{1}-q_{2}\right)-q_{i}-c_{i}\left(I_{i}\right)+\frac{1}{2}(\bar{z}+\underline{z})=0$,

$\frac{\partial V_{i}\left(q_{i}, I_{i}\right)}{\partial I_{i}}=-c_{i}^{\prime}\left(I_{i}\right) q_{i}-I_{i}=0$

The second equation implies that the innovative investment is exactly the marginal cost incurred by innovation multiplying quantity of products.

(2) If $\hat{z}_{i}$ is not an interior point or $\underline{z} \leq \hat{z}_{i}<\bar{z}$ for $i=1,2,(7)$ is rewritten as the following formulation. 


$$
\begin{gathered}
V_{i}\left(q_{i}, I_{i}\right)=\frac{1}{2(\bar{z}-\underline{z})}\left\{q_{i} \bar{z}^{2}+\frac{1}{q_{i}}\left[\left(1+r_{i}\right) D_{i}-\left(A-q_{1}-q_{2}\right) q_{i}+c_{i}\left(I_{i}\right) q_{i}+\frac{1}{2} I_{i}^{2}\right]^{2}\right\} \\
+\frac{\bar{z}}{\bar{z}-\underline{z}}\left[\left(A-q_{1}-q_{2}\right) q_{i}-c_{i}\left(I_{i}\right) q_{i}-\frac{1}{2} I_{i}^{2}-\left(1+r_{i}\right) D_{i}\right] \\
\quad=\frac{1}{2(\bar{z}-\underline{z})}\left\{q_{i}^{\frac{1}{2}} \bar{z}+q_{i}{ }^{-\frac{1}{2}}\left[\left(A-q_{1}-q_{2}\right) q_{i}-c_{i}\left(I_{i}\right) q_{i}-\frac{1}{2} I_{i}^{2}-\left(1+r_{i}\right) D_{i}\right]\right\}^{2}
\end{gathered}
$$

In this case, the solution lies at the corner.

We define function

$$
y_{i}\left(q_{i}, I_{i}\right):=q_{i}^{\frac{1}{2}} \bar{z}+q_{i}^{-\frac{1}{2}}\left[\left(A-q_{1}-q_{2}\right) q_{i}-c_{i}\left(I_{i}\right) q_{i}-\frac{1}{2} I_{i}^{2}-\left(1+r_{i}\right) D_{i}\right] \cdot
$$

Since we have constraint

$$
q_{i} \hat{z}_{i}=\left(1+r_{i}\right) D_{i}-\left[\left(A-q_{1}-q_{2}\right) q_{i}-c_{i}\left(I_{i}\right) q_{i}-\frac{1}{2} I_{i}^{2}\right],
$$

we further achieve relation $y_{i}\left(q_{i}, I_{i}\right)>0$ and solution lies at the corner. Therefore, compared with Brander and Lewis (1986), this study fully considers the solution at the corner.

(3) If $\hat{z}_{i} \geq \bar{z}$, there is no way for debater to lend money to this firm because the debt value equals zero. Since it is not rational, this case is neglected in this paper.

\subsection{Propositions}

For (7), based on the above analysis, we have the following conclusions.

Proposition 1: The solution to function (4) is unique.

Proof. If $\hat{z}_{i}<\underline{z}$ for $i=1,2$, (9) is concave and conclusion is obtained. If $\underline{z} \leq \hat{z}_{i}<\bar{z}$ for $i=1,2$, $V_{i}\left(q_{i}, I_{i}\right)=\frac{1}{2(\bar{z}-\underline{z})} y_{i}^{2}\left(q_{i}, I_{i}\right) \cdot y_{i}\left(q_{i}, I_{i}\right)$ is concave and $y_{i}\left(q_{i}, I_{i}\right)>0 . y_{i}\left(q_{i}, I_{i}\right)$ therefore has unique maximum and $V_{i}\left(q_{i}, I_{i}\right)=\frac{1}{2(\bar{z}-\underline{z})} y_{i}^{2}\left(q_{i}, I_{i}\right)$ reaches its maximum at the corresponding point.
Remark: Proposition 1 holds both for $\hat{z}_{i}<\underline{z}$ and for $\underline{z} \leq \hat{z}_{i}<\bar{z}$. If the solution lies at the corner, $V_{i}\left(q_{i}, I_{i}\right)$ is not concave and there is a unique solution.

If $\hat{z}_{i}$ is not an interior point or $\underline{z} \leq \hat{z}_{i}<\bar{z}$ for $i=1,2$, the solution is determined by the firstorder optimal conditions of $y_{i}\left(q_{i}, I_{i}\right)$.

$\frac{\partial y_{i}\left(q_{i}, I_{i}\right)}{\partial q_{i}}=f_{1}=\frac{1}{2} q_{i}^{-\frac{1}{2}} \bar{z}+\frac{1}{4} q_{i}^{-\frac{3}{2}} I_{i}^{2}+\frac{1}{2} q_{i}^{-\frac{3}{2}}\left(1+r_{i}\right) D_{i}-\frac{1}{2} q_{i}^{-\frac{1}{2}} c_{i}\left(I_{i}\right)+\frac{1}{2} q_{i}^{-\frac{1}{2}}\left(A-q_{j}\right)-\frac{3}{2} q_{i}^{\frac{1}{2}}=0$

$$
\frac{\partial y_{i}\left(q_{i}, I_{i}\right)}{\partial I_{i}}=f_{2}=-c_{i}^{\prime}\left(I_{i}\right) q_{i}^{\frac{1}{2}}-I_{i} q_{i}^{-\frac{1}{2}}=0
$$

$$
\text { If } \underline{z}<\hat{z}_{i}<\bar{z} \text { for } i=1,2, y_{i}\left(q_{i}, I_{i}\right)>0,
$$
a $\mathrm{n}$ d

(13) jointly indicate the following conclusions

Proposition 2: If $\underline{z} \leq \hat{z}_{i}<\bar{z}$ for $i, j=1,2$ and $i \neq j$, then:

(a) Regarding direct effects, we have: (a1) $\frac{\partial q_{i}}{\partial D_{i}}>0, \frac{\partial q_{i}}{\partial r_{i}}>0, \frac{\partial I_{i}}{\partial D_{i}}>0$ and $\frac{\partial I_{i}}{\partial r_{i}}>0$, both debt level and debt rate have positive impacts on output and innovation of the product's firm; (a2) $\frac{\partial V_{i}}{\partial D_{i}} \leq 0$ and $\frac{\partial V_{i}}{\partial r_{i}} \leq 0$, debt level and debt rate have negative effects on the value of shareholders;

(b) Regarding cross effects, we have: (b1) $\frac{\partial q_{j}}{\partial D_{i}}<0, \frac{\partial q_{j}}{\partial r_{i}}<0, \frac{\partial I_{j}}{\partial D_{i}}<0, \frac{\partial I_{j}}{\partial r_{i}}<0$, which mean debt level and debt rate have negative effects on output and innovation of the rival; (b2) $\frac{\partial V_{j}}{\partial D_{i}}<0$ and $\frac{\partial V_{j}}{\partial r_{i}}<0$, both debt level and debt rate decrease the value of the competitor's shareholders; 


$$
\begin{aligned}
\text { (c) Moreover, we get } \frac{\partial\left(V_{i} / D_{i}\right)}{\partial D_{i}}<0 \text { and } \\
\frac{\partial\left(V_{i} / D_{i}\right)}{\partial r_{i}}<0 .
\end{aligned}
$$

Proof: See in Appendix.

Remarks: $\frac{\partial q_{i}}{\partial D_{i}}>0$ manifests that higher debt level causes larger quantity of products. This conclusion is consistent with that of Dixit (1980), and, Brander and Lewis (1986). Higher debate level acts as a commitment of more products to rival. $\frac{\partial q_{i}}{\partial r_{i}}>0$ indicates that higher debate rate also yields larger quantity of products. Furthermore, both more debate and higher rate result in higher innovative investment. Debate level and debate rate act as a commitment, which causes the opponents' reduction of products and innovative investment. Moreover, $\frac{\partial V_{i}}{\partial D_{j}}<0$ and $\frac{\partial V_{i}}{\partial r_{j}}<0$ mean that both higher debt level and higher debt rate efficiently reduce opponents' net profit, in other words, debt has strong strategic influence and it can be taken as a commitment to reduce opponent firms' net profits. This is an extremely interesting conclusion. Under optimal strategy, both debt level and debt rate have no effects on the net profit of the corresponding firms from $\frac{\partial V_{i}}{\partial D_{i}}=0$ and $\frac{\partial V_{i}}{\partial r_{i}}=0$, which is different from Brander and Lewis (1986). $\frac{\partial V_{i}}{\partial D_{i}} \leq 0$ and $\frac{\partial V_{i}}{\partial r_{i}} \leq 0$ illustrate that debt level and debt rate have negative effects on the value of shareholders, so firms will make decisions based on $\frac{\partial V_{i}}{\partial D_{i}}=0$ and $\frac{\partial V_{i}}{\partial r_{i}}=0$ to relieve the negative effects of debt. That means debt has no effects on the corresponding firms' value or net profits under optimal strategy. $\frac{\partial\left(V_{i} / D_{i}\right)}{\partial D_{i}}<0$ and $\frac{\partial\left(V_{i} / D_{i}\right)}{\partial r_{i}}<0$ imply that unit debt yielding net profit reduces with higher debt level and higher debt rate.

The balance is discussed for $\hat{z}_{i}<\underline{z}$. Based on (12) and (13), we achieve

Proposition 3: If $\hat{z}_{i}<\underline{z}$ for $i=1,2$, then:

(a) Neither firms' innovative investment strategy nor quantity strategy are related to to debate level and rate;

(b) The operating profit of firms satisfies the following relation $\frac{\partial V_{i}}{\partial D_{i}}<0$ and $\frac{\partial V_{i}}{\partial r_{i}}<0$. $\frac{\partial\left(V_{i} / D_{i}\right)}{\partial D_{i}}<0$ and $\frac{\partial\left(V_{i} / D_{i}\right)}{\partial r_{i}}<0 ;$

$\frac{\partial W_{i}}{\partial r_{i}}>0$, or both debt level and debt rate increase the debt value.

\section{Proof. See in Appendix.}

Remarks: If $\hat{z}_{i}<\underline{z}$, both higher debate level and higher rate reduce operating profit. Debate-holder also benefits much more both under higher debate level and under higher rate if $\hat{z}_{i}<\underline{z}$.

We further discuss the other situation. One firm is in good state while the other firm satisfies $\underline{z} \leq \hat{z}_{i}<\bar{z}$. Without loss of generality, we assume that $\hat{z}_{1}<\underline{z}$ and $\underline{z} \leq \hat{z}_{2}<\bar{z}$. This case is very popular in economics. In some industries, for example, some firms undertake debate while 
others have no debate. It is crucial to address this type of industry. From (12) and (13), we have

$$
\begin{gathered}
\left(A-q_{1}-q_{2}\right)-q_{1}-c_{1}\left(I_{1}\right)=0, \\
-c_{1}^{\prime}\left(I_{1}\right) q_{1}-I_{1}=0 .
\end{gathered}
$$

For the second firm, we have

$\frac{1}{2} q_{2}{ }^{-\frac{1}{2}} \bar{z}+\frac{1}{4} q_{2}{ }^{-\frac{3}{2}} I_{2}{ }^{2}+\frac{1}{2} q_{2}{ }^{-\frac{3}{2}}\left(1+r_{2}\right) D_{2}-\frac{1}{2} q_{2}{ }^{-\frac{1}{2}} c_{2}\left(I_{2}\right)+\frac{1}{2} q_{2}{ }^{-\frac{1}{2}}\left(A-q_{1}\right)-\frac{3}{2} q_{2}{ }^{\frac{1}{2}}=0$

In this situation, from Proposition 2 and Proposition 3 we immediately have the following conclusion

Proposition 4: If $\hat{z}_{1}<\underline{z}$ and $\underline{z} \leq \hat{z}_{2}<\bar{z}$, then

(a) Neither firms' innovative investment strategy nor quantity strategy are related to the first firm's debate level and rate. Moreover, $\frac{\partial W_{1}}{\partial D_{1}}>0$ and $\frac{\partial W_{1}}{\partial r_{1}}>0$;

(b) For direct effects, we have (b1) $\frac{\partial q_{2}}{\partial r_{2}}>0$, $\frac{\partial q_{2}}{\partial D_{2}}>0, \frac{\partial I_{2}}{\partial D_{2}}>0, \frac{\partial I_{2}}{\partial r_{2}}>0$; for cross effects, we have $\frac{\partial q_{1}}{\partial D_{2}}<0, \frac{\partial q_{1}}{\partial r_{2}}<0$

$$
\begin{gathered}
\text { (c) Moreover, } \frac{\partial V_{1}}{\partial D_{2}}<0, \frac{\partial V_{1}}{\partial r_{2}}<0, \\
\frac{\partial\left(V_{i} / D_{i}\right)}{\partial D_{i}}<0 \text { and } \frac{\partial\left(V_{i} / D_{i}\right)}{\partial r_{i}}<0 .
\end{gathered}
$$

Remarks: For the first firm, conclusions are similar to Proposition 3. For the second firm, results similar to Proposition 2 are achieved.
In summary about three cases, monopoly debater benefits from higher debt rate while firm's net profits are reduced because of higher debt levels and higher debt rate. Debt levels are an important type of commitment to vary opponent's strategies.

\section{Concluding remarks}

Capital structure-industrial organization is an important issue both for corporate finance and industrial organization. Understanding the interaction between capital structure and product market competition is critical for decision maker of firms. Imperfect competition assumption is more suitable than perfect assumption. So the relationship between financial structure and innovative investment under duopoly is captured in this article. This paper characterizes duopoly industry with limited liability effects.

This paper reveals the influence of debts on firms' innovation behavior and firms' value. The results of this study show that shareholder value of opponent firms is reduced with higher debt levels and higher debt rate. Debt has strategic effects and it can be regarded as fierce competition commitment to rivals. On one hand, higher debt levels and higher debt rate all suggest more innovative investment for the product firm. On the other hand, the increase in debt level and debt rate inhibits opponents' innovation. Our study makes a significant theoretical development of the capital structure-industrial organization framework.

This paper has no restriction about interior point solution, which may support a useful outlet to discuss the relationship between financial structure and firms' behaviors. This study highlights innovation with limited liability effect and no bankruptcy cost is introduced. We extend Blander and Lewis (1986) theory in three aspects: Firstly, this paper employs Blander and Lewis' framework (1986) to analyze other output market competition (innovative investment). Secondly, we expand capital market from perfect competition to monopoly, which makes it easy to 
analyze the effect of the cost of debt financing on output market competition. Finally, the optional solutions are more common than that in Blander and Lewis (1986), because this study has no restriction of interior point solution. When other factors are considered, the effects of debt levels seem more complicated, and those are our further researching topics. Besides, other competition behaviors such as advertising and merger can also be analyzed with this framework.

\section{Notes}

1 This seems like that in Sacco and Schmutzler (2011).

2 If $r_{1}=r_{2}$, the monopolization debater supports debate to two firms with uniform price. Otherwise, there is price discrimination. Inderst and Shaffer (2009) introduced price discrimination, see also in (Inderst \& Valetti, 2009). Furthermore, $r_{i}$ is strictly regulated by national policies or laws.

\section{References}

Baum, C. F., Chakraborty, A., \& Liu, B. Y. (2010). The impact of macroeconomic uncertainty on firms' changes in financial leverage. International Journal of Finance \& Economics, 15(1), 22-30.

Bhattacharyya, S. (2013). Political origins of financial structure. Journal of Comparative Economics, 41(4), 979-994.

Brander,J. A., \& Lewis, T. R. (1986). Oligopoly and financial structure: The limited liability effect. American Economic Review, 76(5), 956-970.

Brander, J. A., \& Lewis, T. R. (1988). Bankruptcy costs and the theory of oligopoly, Canadian Journal of Economics, 21(2), 221-243.

Chen, Y. H., Nie, P. Y., \& Wen, X. W. (2015). Analysis of innovation based on financial structure. Economic Research-Ekonomska Istraživanja, 28(1), 631-640.

Chevalier, J. A. (1995). Capital structure and product-market competition: Empirical evidence from the supermarket industry. American Economic Review, 85(3), 415-435.
Chowdhuri, J., \& Haller, H. (2009). Debt financing and output market behavior [Technique Report], Virginia Polytechnic Institute and State University.

Clayton, M. J. (2009). Debt, investment, and product market competition: A note on the limited liability effect. Journal of Banking \& Finance, 33(4), 694-700.

Cull, R., Demirgüç-Kunt, A., \& Lin, J. Y. (2013). Financial structure and economic development: a reassessment. The World Bank Economic Review, 27(3), 470-475.

Dixit, A. (1980). The role of investment in entry deterrence. Economic Journal, 90(357), 95-106.

Inderst, R., \& Shaffer, G. (2009). Market power, price discrimination, and allocative efficiency in intermediate-goods markets. Rand Journal of Economics, 40(4), 658-672.

Inderst, R., \& Valetti,T. (2009). Price discrimination in input markets. Rand Journal of Economics, 40(1), 1-19.

Jacob, J., \& Spaeter, S. (2016). Large-scale risks and technological change: What about limited liability?' Journal of Public Economic Theory, 18(1), 125-142.

Jansen, M. C., \& Meckling, W. (1976). Theory of the firm: Managerial behavior, agency costs, and capital structure. Journal of Financial Economics, 3(4), 305-360.

Maksimovic, V. (1988). Capital structure in repeated oligopolies. Rand Journal of Economics, 19(3), 389-407.

Modigliani, F., \& Miller, M. H. (1958). The cost of capital, corporation finance and the theory of investment. The American Economic Review, 48(3), 261-297.

Myers, S. C. (1977). Determination of corporate borrowing. Journal of Financial Economics, 5, 147-175. 
Norman, I. (2004). Technology choice bias and limited liability. Economics of Governance, 5(2), 103-118.

Nie, P. Y., \& Chen, Y. H. (2012). Duopoly competitions with capacity constrained input. Economic Modelling, 29(5), 1715-1721.

Nie, P. Y., Chen, Y. H., Yang, Y. C., \& Wang, X. H. (2016). Subsidies in carbon finance for promoting renewable energy development. Journal of Cleaner Production, 139, 677-684.

Nie, P. Y., Yang, Y. C., Chen, Y. H., \& Wang, Z. H. (2016). How to subsidize energy efficiency under duopoly efficiently? Applied Energy, 175, 31-39.

Ramalho, J. J. S., \& Da Silva, J. V. (2009). A twopart fractional regression model for the financial leverage decisions of micro, small, medium and large firms. Quantitative Finance, 9(5), 621-636.

Riordan, M. H. (2003). How do capital markets influence product market competition? Review of Industrial Organization, 23(3-4), 179-191.

Sacco, D., \& Schmutzler, A. (2011). Is there a U-shaped relation between competition and investment. International Journal of Industrial Organization, 29(1), 65-73.
Schmitz, P. (2012). The hold-up problem, innovations, and limited liability. Economics Letters, 117(3), 841-843.

Showalter, D. M. (1995). Oligopolyand financial structure: Commen. The American Economic Review, 85(3), 647-653.

Showalter, D. M. (2010). Entry deterrence through credit denial. International Review of Economics \& Finance, 19(4), 539-554.

Tarzijan, J. (2007). Capital structure and entry deterrence with multiple incumbents. The B.E. Journal of Economic Analysis \& Policy, 7(1), 1-6.

Uras, B. R. (2014). Corporate financial structure, misallocation and total factor productivity. Journal of Banking \& Finance, 39(1), 177-191.

Vives, X. (2008). Innovation and competitive pressure. The Journal of Industrial Economics, 56(3), 419-469.

Wang, K.-C. A., Wang, Y.-J, Liang, W.-J., Tsai, M.-C., \& Mai, C.-C. (2016). Patent licensing under financial structure with limited liability. International Review of Economics \& Finance, $46,121-135$. 


\section{Appendix}

\section{Proof of Proposition 2}

Relation $\frac{\partial f_{1}}{\partial q_{i}}=-\frac{1}{4} q_{i}^{-\frac{3}{2}} \bar{z}-\frac{3}{8} q_{i}^{-\frac{5}{2}} I_{i}^{2}-\frac{3}{4} q_{i}^{-\frac{5}{2}}\left(1+r_{i}\right) D_{i}+\frac{1}{4} q_{i}^{-\frac{3}{2}} c_{i}\left(I_{i}\right)-\frac{1}{4} q_{i}^{-\frac{3}{2}}\left(A-q_{j}\right)-\frac{3}{4} q_{i}^{-\frac{1}{2}}<0$ $\frac{\partial f_{1}}{\partial q_{j}}=-\frac{1}{2} q_{i}^{-\frac{1}{2}}<0, \frac{\partial f_{1}}{\partial I_{j}}=0$ and $\frac{\partial f_{1}}{\partial I_{i}}=\frac{1}{2} q_{i}^{-\frac{3}{2}} I_{i}-\frac{1}{2} q_{i}^{-\frac{1}{2}} c_{i}^{\prime}\left(I_{i}\right)=0$ simultaneously hold apparently. Furthermore, we have $\frac{\partial f_{1}}{\partial r_{i}}=\frac{1}{2} q_{i}^{-\frac{3}{2}} D_{i}>0$ and $\frac{\partial f_{1}}{\partial D_{i}}=\frac{1}{2} q_{i}^{-\frac{3}{2}}\left(1+r_{i}\right)>0$. (13) implies $\frac{\partial f_{2}}{\partial I_{i}}<0, \frac{\partial f_{2}}{\partial I_{j}}=0, \frac{\partial f_{2}}{\partial q_{j}}=0$ and $\frac{\partial f_{2}}{\partial q_{i}}>0$. Moreover, (12) indicates the relation $\frac{\partial f_{1}}{\partial q_{i}} d q_{i}+\frac{\partial f_{1}}{\partial q_{j}} d q_{j}=0$. (13) implies $\frac{\partial f_{2}}{\partial q_{i}} d q_{i}+\frac{\partial f_{1}}{\partial I_{i}} d I_{i}=0$. By implicit function theorem, there exists unique and differentiable function $q_{i}\left(D_{i}, r_{i}, D_{j}, r_{j}\right)$ and $I_{i}\left(D_{i}, r_{i}, D_{j}, r_{j}\right)$ for $i=1,2$. Denote $f_{1}(i=1)$ to be (12) with $i=1$ and similar definition for $f_{1}(i=2), f_{2}(i=1)$ and $f_{2}(i=2)$. These implicit functions satisfy the following relation.

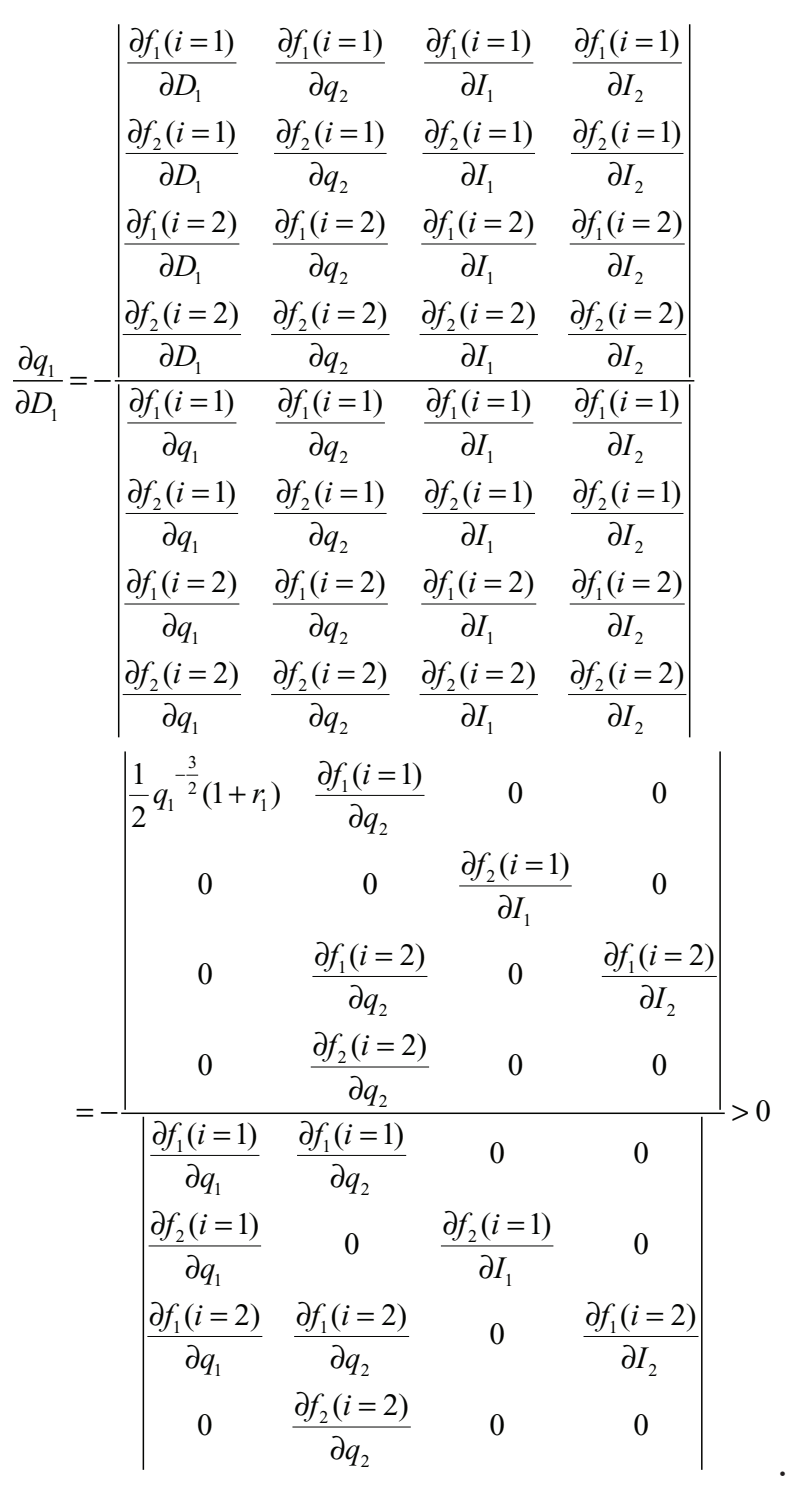


We achieve $\frac{\partial q_{1}}{\partial D_{1}}>0 . \frac{\partial f_{1}}{\partial q_{i}} d q_{i}+\frac{\partial f_{1}}{\partial q_{j}} d q_{j}=0$ implies $\frac{\partial q_{1}}{\partial D_{2}}<0$. Similarly, we have $\frac{\partial q_{2}}{\partial D_{2}}>0$. Similarly, we have the relations $\frac{\partial q_{j}}{\partial D_{i}}<0, \frac{\partial q_{j}}{\partial r_{i}}<0, \frac{\partial I_{j}}{\partial r_{i}}<0, \frac{\partial q_{i}}{\partial D_{i}}>0, \frac{\partial q_{i}}{\partial r_{i}}>0, \frac{\partial I_{i}}{\partial D_{i}}>0$ and $\frac{\partial I_{i}}{\partial r_{i}}>0$.

We further argue $\frac{\partial V_{i}}{\partial D_{j}}<0, \frac{\partial V_{i}}{\partial r_{j}}<0, \frac{\partial V_{i}}{\partial D_{i}}=0$ and $\frac{\partial V_{i}}{\partial r_{i}}=0$ by envelop theorem. From the above analysis, we have $\frac{\partial q_{j}}{\partial D_{i}}=-q_{i}^{-1}\left(1+r_{i}\right)$ and $\frac{\partial q_{j}}{\partial r_{i}}=-q_{i}^{-1} D_{i}$.

$$
\begin{aligned}
& \frac{\partial V_{i}}{\partial D_{j}}=\frac{\partial V_{i}}{\partial q_{i}} \frac{\partial q_{i}}{\partial D_{j}}+\frac{\partial V_{i}}{\partial I_{i}} \frac{\partial I_{i}}{\partial D_{j}}+\frac{\partial V_{i}}{\partial q_{j}} \frac{\partial q_{j}}{\partial D_{j}}+\frac{\partial V_{i}}{\partial I_{j}} \frac{\partial I_{j}}{\partial D_{j}} \\
& =-\frac{1}{\bar{z}-\underline{z}} y_{i} q_{i}^{\frac{1}{2}} \frac{\partial q_{j}}{\partial D_{j}}<0
\end{aligned}
$$

$$
\begin{aligned}
\frac{\partial V_{i}}{\partial r_{j}} & =\frac{\partial V_{i}}{\partial q_{i}} \frac{\partial q_{i}}{\partial r_{j}}+\frac{\partial V_{i}}{\partial q_{j}} \frac{\partial q_{j}}{\partial r_{j}}+\frac{\partial V_{i}}{\partial I_{i}} \frac{\partial I_{i}}{\partial r_{j}}+\frac{\partial V_{i}}{\partial I_{j}} \frac{\partial I_{j}}{\partial r_{j}} \\
& =-\frac{1}{\bar{z}-\underline{z}} y_{i} q_{i}^{\frac{1}{2}} \frac{\partial q_{j}}{\partial r_{j}}<0,
\end{aligned}
$$

$$
\begin{aligned}
& \frac{\partial V_{i}}{\partial D_{i}}=\frac{\partial V_{i}}{\partial q_{i}} \frac{\partial q_{i}}{\partial D_{i}}+\frac{\partial V_{i}}{\partial I_{i}} \frac{\partial I_{i}}{\partial D_{i}}+\frac{\partial V_{i}}{\partial q_{j}} \frac{\partial q_{j}}{\partial D_{i}}+\frac{\partial V_{i}}{\partial I_{j}} \frac{\partial I_{j}}{\partial D_{i}}-y_{i} q_{i}^{-\frac{1}{2}}\left(1+r_{i}\right) \\
& \quad=-\frac{1}{\bar{z}-\underline{z}} y_{i} q_{i}^{\frac{1}{2}} \frac{\partial q_{j}}{\partial D_{i}}-\frac{1}{\bar{z}-\underline{z}} y_{i} q_{i}^{-\frac{1}{2}}\left(1+r_{i}\right)=\frac{y_{i}}{\bar{z}-\underline{z}}\left(-q_{i}^{\frac{1}{2}} \frac{\partial q_{j}}{\partial D_{i}}-q_{i}^{-\frac{1}{2}}\left(1+r_{i}\right)\right) \leq 0
\end{aligned}
$$

$$
\begin{aligned}
\frac{\partial V_{i}}{\partial r_{i}} & =\frac{\partial V_{i}}{\partial q_{i}} \frac{\partial q_{i}}{\partial r_{i}}+\frac{\partial V_{i}}{\partial q_{j}} \frac{\partial q_{j}}{\partial r_{i}}+\frac{\partial V_{i}}{\partial I_{i}} \frac{\partial I_{i}}{\partial r_{i}}+\frac{\partial V_{i}}{\partial I_{j}} \frac{\partial I_{j}}{\partial r_{i}}-y_{i} q_{i}^{-\frac{1}{2}} D_{i} \\
& =-\frac{1}{\bar{z}-\underline{z}} y_{i} q_{i}^{\frac{1}{2}} \frac{\partial q_{j}}{\partial r_{i}}-\frac{1}{\bar{z}-\underline{z}} y_{i} q_{i}^{-\frac{1}{2}} D_{i}=\frac{y_{i}}{\bar{z}-\underline{z}}\left(-q_{i}^{\frac{1}{2}} \frac{\partial q_{j}}{\partial r_{i}}-q_{i}^{-\frac{1}{2}} D_{i}\right) \leq 0
\end{aligned}
$$


The term $\frac{\partial V_{i}}{\partial q_{j}} \frac{\partial q_{j}}{\partial D_{i}}$ manifests the commitment effects of debt, which yields the strategy change of opponent and this firm benefits from this commitment. $\frac{\partial\left(V_{i} / D_{i}\right)}{\partial D_{i}}<0$ and $\frac{\partial\left(V_{i} / D_{i}\right)}{\partial r_{i}}<0$ apparently hold.

The conclusions are achieved and the proof is complete.

\section{Proof of Proposition 3}

If $\hat{z}_{i}<\underline{z}$ for $i=1,2$,(7) implies (9) and (10). By virtue of (9) and (10), we immediately obtain that neither firms' innovative investment strategy nor quantity strategy have relation to debate level and rate.

Envelope theorem for (7) implies that $\frac{\partial V_{i}}{\partial D_{i}}<0$ and $\frac{\partial V_{i}}{\partial r_{i}}<0$. Envelop theorem for (6) suggests $\frac{\partial W_{i}}{\partial D_{i}}>0$ and $\frac{\partial W_{i}}{\partial r_{i}}>0$. Obviously, we achieve the relation $\frac{\partial\left(V_{i} / D_{i}\right)}{\partial D_{i}}<0$ and $\frac{\partial\left(V_{i} / D_{i}\right)}{\partial r_{i}}<0$. Conclusions are achieved and the proof is complete.

\section{Proof of Proposition 4}

Proposition 3 indicates that neither firms' innovative investment strategy nor quantity strategy are related to the first firm's debate level and rate. Furthermore, $\frac{\partial W_{1}}{\partial D_{1}}>0$ and $\frac{\partial W_{1}}{\partial r_{1}}>0$ all hold. Proposition 2 yields the relation $\frac{\partial q_{1}}{\partial D_{2}}<0, \frac{\partial q_{1}}{\partial r_{2}}<0, \frac{\partial q_{2}}{\partial r_{2}}>0, \frac{\partial q_{2}}{\partial D_{2}}>0, \frac{\partial I_{2}}{\partial D_{2}}>0$ and $\frac{\partial I_{2}}{\partial r_{2}}>0 . \frac{\partial\left(V_{i} / D_{i}\right)}{\partial D_{i}}<0$ and $\frac{\partial\left(V_{i} / D_{i}\right)}{\partial r_{i}}<0$ apparently hold by virtue of Proposition 2 and Proposition 3. Conclusions are achieved and the proof is complete. 


\section{Supporting agencies:}

This work is partially supported by GDUPS (2012), National Natural Science Foundation of PRC (71271100, 71401057), Guangdong Social Science Foundation (GD13YLJ02), The Soft Science Project of Guangdong Province (2014A070704008), Collaborative Innovation Center of Scientific Finance \& Industry, and Innovative Group Foundation (Humanities and Social Sciences) for Higher Education of Guangdong Province (2015WCXTD009).

\section{About the authors:}

1. You-hua Chen, Ph.D of economics from Jinan University, Guangzhou City of China in 2013. E-mail: University,chenyhua214@163.com.

2. Pu-yan Nie, Ph.D of Mathematics from Chinese Academy of Science, Beijing City of China in 2003. E-mail: pynie2013@163.com

3. Jin-bo Huang, Ph.D of Management from Sun Yat-sen University, Guangzhou City of China in 2012. E-mail:357720116@qq.com

\section{Contribution of each author:}

\begin{tabular}{lccc}
\hline Contribution & You-hua Chen & Pu-yan Nie & Jin-bo Huang \\
\hline 1. Definition of research problem & $\sqrt{ }$ & $\sqrt{ }$ \\
2. Development of hypotheses or research questions (empirical studies) & $\sqrt{ }$ & $\sqrt{ }$ \\
3. Development of theoretical propositions (theoretical Work) & & $\sqrt{ }$ & \\
4. Theoretical foundation/ Literature review & & & $\sqrt{ }$ \\
5. Definition of methodological procedures & & $\sqrt{ }$ \\
6. Data collection & $\sqrt{ }$ & \\
7. Statistical analysis & & & $\sqrt{ }$ \\
8. Analysis and interpretation of data & & & \\
9. Critical revision of the manuscript & $\sqrt{ }$ & \\
10. Manuscript Writing & & $\sqrt{ }$ & \\
\hline
\end{tabular}

